\title{
Differential effects of nitric oxide synthase inhibitors in an in vivo allergic rat model
}

\author{
M.K. Tulić*, ${ }^{+}$, J.L. Wale*, P.G. Holt ${ }^{\#}$, P.D. Sly ${ }^{+}$
}

Differential effects of nitric oxide synthase inhibitors in an in vivo allergic rat model. M.K Tulić, J.L. Wale, P.G. Holt, P.D. Sly. C)ERS Journals Ltd 2000.

ABSTRACT: The in vivo role of nitric oxide in inflammatory cell migration, vascular permeability and the development of hyperresponsiveness to methacholine (MCh) was studied in rats $24 \mathrm{~h}$ following ovalbumin (OVA) challenge.

The NO synthase (NOS) inhibitors $N^{\mathrm{G}}$-mono-methyl-L-arginine (L-NMMA; nonselective), aminoguanidine (two-fold inducible NOS-selective), $N^{\omega}$-nitro-L-arginine methyl ester (L-NAME; 2000-fold endothelial cell NOS-selective) or $S$-methyl-L-thiocitrulline (100-fold neuronal NOS-selective) were administered $\left(100 \mathrm{mg} \cdot \mathrm{kg}^{-1}\right.$ s.c.) to OVA-sensitized Piebald-Virol-Glaxo rats on 3 consecutive days during which they were challenged with allergen (1\% OVA). Responses to inhaled MCh were measured in anaesthetized animals $24 \mathrm{~h}$ after OVA challenge. Cellular inflammation and vascular permeability were assessed using bronchoalveolar lavage (BAL) fluid collected $30 \mathrm{~min}$ after administration of Evans blue (50 mg kg ${ }^{-1}$ i.v.).

OVA challenge in sensitized animals induced hyperresponsiveness to $\mathrm{MCh}$, inflammatory cell influx and increased leakage of Evans blue into the BAL fluid $(n=9$, $\mathbf{p}<\mathbf{0 . 0 0 1})$. Aminoguanidine was effective in inhibiting the allergen-induced cellular influx and microvascular leakage $(n=9, p<0.001)$ without altering responses to MCh. This effect was reserved by L-arginine. L-NAME $(n=5, p<0.01)$ and $S$-methyl-L-thiocitrulline $(n=6, p<0.001)$ further potentiated the allergen-induced hyperresponsiveness without altering cellular inflammation. L-NMMA attenuated both the OVA-induced cellular influx and Evans blue leakage $(n=8, p<0.001)$ as well as further potentiating the hyperresponsiveness to $\mathrm{MCh}(\mathbf{p}<\mathbf{0 . 0 5})$.

From these studies, it is suggested that, in allergic Piebald-Virol-Glaxo rats, nitric oxide production by inducible nitric oxide synthase plays a role in the migration of inflammatory cells and increase in vascular permeability following allergen challenge, whereas nitric oxide produced by the constitutively expressed neuronal nitric oxide synthase limits hyperresponsiveness to methacholine.

Eur Respir J 2000; 15: 870-877.
*Divisions of Clinical Sciences and ${ }^{\#}$ Cell Biology, TVW Telethon Institute for Child Health Research and ${ }^{+}$Dept of Paediatrics, University of Western Australia, Perth, Australia.

Correspondence: M.K. Tulić

Division of Clinical Sciences

TVW Telethon Institute for Child Health Research

P.O. Box 855

West Perth

WA 6872

Australia

Fax: 61894897700

Keywords: Allergic inflammation hyperresponsiveness

inducible nitric oxide synthase neuronal nitric oxide synthase nitric oxide synthase inhibitors

Received: June 131999

Accepted after revision February 122000

This study was supported by a grant from the National Health and Medical Research Council, Australia and M.K. Tulć holds the Asthma Foundation of Western Australia Inaugural $\mathrm{PhD}$ Scholarship.
Nitric oxide plays a key role as a regulator of multiple biological functions including vasodilation, neurotransmission and mediation of the immune and inflammatory responses against intracellular pathogens [1]. NO has been recognized as an important immunomodulatory and cytotoxic mediator of inflammatory responses in the lungs. It is produced in the lungs from the endogenous amino acid L-arginine by the enzyme NO synthase (NOS), which exists in several isoforms. Of the three isoforms of NOS, two are constitutively-expressed (cNOS), endothelial cell NOS (eNOS) and neuronal NOS (nNOS). These are present under basal conditions and are activated by an increase in intracellular calcium ions, forming a small amount of NO which contributes to local physiological regulation. The third form of NOS is an inducible form (iNOS) which is thought to be involved in inflammatory diseases of the airways and in host defence against infection. Activation of iNOS upon stimulation with proinflammatory cytokines such as tumour necrosis factor- $\alpha$, interleukin-1 $\beta$ (IL-1 $\beta$ ), interferon gamma and/or endotoxin results in production of large amounts of $\mathrm{NO}$, the production continuing for many hours and having widespread effect. Production of NO by iNOS has been shown to be involved in bronchial vascular dilation and leakage $[2,3]$ as well as in amplifying and perpetuating the Thelper cell 2-mediated inflammatory response in vitro [4].

Chronic asthma, especially in adults, is thought to be the clinical expression of chronic inflammation, resulting from chronic exposure to environmental factors, including allergens. Following allergen exposure in sensitized individuals, an acute deterioration in lung function occurs within 15-30 min, with spontaneous recovery within 1-2 h. This is frequently followed by a late-phase reaction, with a secondary fall in lung function, influx of inflammatory cells, especially eosinophils, and an increase in airway responsiveness to stimuli such as methacholine (MCh).

Clinical studies have detected increased levels of $\mathrm{NO}$ in the exhaled air of asthmatics [5, 6] and increased expression of iNOS in bronchial epithelial cells from these patients [7]. Data such as these have raised hopes that exhaled NO may be useful as a noninvasive marker of chronic inflammation in the airways that could be used to 
monitor the response to anti-inflammatory treatments, such as inhaled steroids.

Previous studies in rats have shown $N^{\omega}$-nitro-L-arginine methyl ester (L-NAME) to inhibit the lipopolysaccharideinduced airway hyporesponsiveness normally observed 9-12 $\mathrm{h}$ following bacterial exposure [8]. Under physiological conditions, endogenous NO inhibits microvascular permeability; however, when iNOS is expressed, the increased production of NO enhances this leakage [9]. In Brown Norway rats, aminoguanidine has been shown to increase IL-1 $\beta$-induced bronchial responsiveness to bradykinin but not to acetylcholine, without having any effect on IL-1 $\beta$-induced neutrophilia [10]. Further studies have demonstrated L-NAME to produce no effect on the total or differential cell count in sensitized rats 6 or $24 \mathrm{~h}$ following allergen challenge with ovalbumin (OVA) but

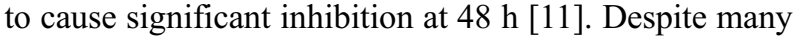
studies, the role of NO in allergic inflammation is still unknown and the functional role of the different NOS isoenzymes remains controversial.

It was hypothesized that different NOS enzymes may be involved in regulating different aspects of the late-phase components of the allergic inflammatory response. The purpose of this study was to investigate the effect of four NOS inhibitors, NG-mono-methyl-L-arginine (L-NMMA; nonselective), aminoguanidine (two-fold iNOS-selective), L-NAME (2,000-fold eNOS-selective) and $S$-methyl-Lthiocitrulline (100-fold nNOS-selective), on lung function, inflammatory cell influx and the leakage of Evans blue into the bronchoalveolar lavage (BAL) fluid of sensitized and allergen-challenged Piebald-Virol-Glaxo (PVG) rats.

\section{Methods}

An in vivo animal model of allergic inflammation was used allowing study of the various components of the inflammatory response including inflammatory cell migration, microvascular permeability and hyperresponsiveness using the forced oscillation technique. This technique allows bronchoconstrictor responses to be separated into parenchymal and airway components, and thereby determination of the site of action of spasmogens in the allergic inflammatory response.

\section{Animals}

Male PVG rats weighing 200-280 g (Research Centre, Institute for Child Health Research, Perth, Australia), housed in a clean animal house environment, kept on an OVA-free diet and with ad libitum access to water and food were studied at 10 weeks of age. The study protocol was approved by the Institutional Animal Ethics Committee.

\section{Sensitization procedure}

Animals were actively sensitized on day 0 via a single i.p. injection of OVA $(100 \mu \mathrm{g}$ in phosphate-buffered saline (PBS) $\mathrm{pH} 7.2$ ) along with the immunoglobulin $\mathrm{E}(\mathrm{IgE})-$ selective adjuvant ricin $(50 \mathrm{ng})$. The animals were placed in a Plexiglass chamber 10-14 days after sensitization, at the peak of their IgE response $[12,13]$, and challenged with aerosolized OVA (1\%) for $30 \mathrm{~min}$. The aerosols were generated by an ultrasonic nebulizer (De Vilbiss Ultra-Neb $^{\text {TM }}$ 2000; Sunrise Medical, Somerset, PA, USA), the outlet of which was connected to the chamber. The output of the nebulizer was $0.5 \mathrm{~mL} \cdot \mathrm{min}^{-1}$ and the mean particle size was $3.5 \mu \mathrm{m}$ (manufacturer's specifications).

\section{Pretreatment with nitric oxide synthase inhihitors}

The NOS inhibitors (L-NMMA, L-NAME, aminoguanidine or $S$-methyl-L-thiocitrulline) were administered s.c. at a dose of $100 \mathrm{mg} \cdot \mathrm{kg}^{-1}$ to OVA-sensitized PVG rats on 3 consecutive days (fig. 1). The first and second doses were given $23 \mathrm{~h}$ and $1 \mathrm{~h}$ prior to allergen challenge respectively. The last dose was given $23 \mathrm{~h}$ after OVA challenge, 1 $\mathrm{h}$ prior to administration of anaesthesia. Measurement of lung function, and cellular influx and Evans blue concentration in the BAL fluid was assessed $24 \mathrm{~h}$ after allergen challenge in sensitized animals.

Four groups of naive animals received either L-arginine (or the inactive enantiomer D-arginine), L-NAME or a similar volume of saline s.c. at a dose of $100 \mathrm{mg} \cdot \mathrm{kg}^{-1}$ on 3 consecutive days, the last dose being given $1 \mathrm{~h}$ prior to anaesthesia and measurements.

\section{Animal preparation}

The animals were anaesthetized by i.m. injection of xylazine $\left(12 \mathrm{mg} \cdot \mathrm{kg}^{-1}\right)$ and ketamine $\left(40 \mathrm{mg} \cdot \mathrm{kg}^{-1}\right) 24 \mathrm{~h}$ after OVA challenge and prepared for measurement of lung function. They were placed in the supine position and a femoral vein cannulated with polyethylene tubing for the intravenous injection of drugs. Tracheostomy was performed and a metal cannula (length $10 \mathrm{~mm}$, inside diameter (ID) $2 \mathrm{~mm}$ ) inserted into the trachea. The animals were mechanically ventilated (Harvard Rodent Ventilator Model 683; Harvard Apparatus, South Natick, MA, USA) at a frequency of 90 breaths $\mathrm{min}^{-1}$ with a tidal volume of 2 $\mathrm{mL}$. During mechanical ventilation, a sigh (double tidal volume) was delivered every $5 \mathrm{~min}$ to prevent atelectasis. The end-expiratory pressure was set at $2.5 \mathrm{cmH}_{2} \mathrm{O}$. The thorax was opened by means of midline sternotomy and the ribs were widely retracted. Muscle relaxation was achieved with pancuronium bromide $\left(0.2 \mathrm{mg} \cdot \mathrm{kg}^{-1}, i . v\right.$. $)$ and maintenance doses of anaesthetic and muscle relaxant were

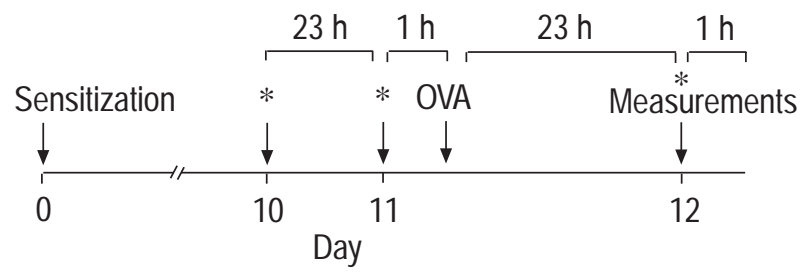

Fig. 1. - Pretreatment protocol time-bar. Sensitized Piebald-Virol-Glaxo rats were pretreated with nitric oxide synthase inhibitors $\left(N^{\mathrm{G}}\right.$-monomethyl-L-arginine, $N^{\omega}$-nitro-L-arginine methyl ester aminoguanidine or $S$ methyl-L-thiocitrulline) on 3 consecutive days $\left(100 \mathrm{mg} \cdot \mathrm{kg}^{-1}\right.$ s.c.) $\left({ }^{*}\right)$, during which time they were challenged with the allergen $(1 \%$ ovalbumin (OVA)). The first and the second doses of the drugs were administered 23 and $1 \mathrm{~h}$ prior to the OVA challenge, respectively. The last dose was given $23 \mathrm{~h}$ after OVA challenge, $1 \mathrm{~h}$ prior to measurements of lung function, cellular influx and Evans blue concentration in the bronchoalveolar lavage fluid being made. 
administered i.v. every $45 \mathrm{~min}$. The electrocardiogram and cardiac frequency were monitored continuously using limb leads connected to a standard electrocardiograph (78342A; Hewlett Packard Co., Boise, ID, USA).

\section{Measurement of respiratory mechanics}

Lung input impedance $(Z \mathrm{~L})$ was measured using an adaptation of the low-frequency forced oscillation technique, in which pressure is measured at either end of the wave tube [14]. Briefly, measurements were made by applying loudspeaker-generated small-amplitude oscillatory signals of $0.5-20 \mathrm{~Hz}$ through a 114-cm-long 1.45mm-ID polyethylene wave tube during a 6-s apnoeic period. A three-way tap was used to switch the animal from the respirator to a loudspeaker-in-box system at endexpiration. The pressure in the loudspeaker was adjusted to $2.5 \mathrm{cmH}_{2} \mathrm{O}$ to keep the transpulmonary pressure constant during measurements. Two identical pressure transducers (ICS model 33NA002D; ICSensors Inc., Milpitos, CA, USA) were used to measure the pressures at the loudspeaker and at the tracheal cannula end of the wave tube. ZL was calculated as described by Рет́́K et al. [14]. In order to separate airway and tissue mechanics, a model containing frequency-independent airway resistance ( $R \mathrm{aw})$ and inertance (Iaw) in series with a constant-phase tissue model including frequency-dependent tissue resistance $(G)$ and tissue elastance $(H)$ was fitted to the $Z \mathrm{~L}$ spectra by minimizing the differences between the measured and modelled impedance [15]. Impedances coinciding with cardiac frequency and its harmonics were omitted from the model fitting since cardiac activity caused a low signal-tonoise ratio at these frequency components.

\section{Study protocol}

Following an equilibration period of $15 \mathrm{~min}$, baseline was established by means of four to six $Z \mathrm{~L}$ measurements. Cumulative doses of MCh $\left(2-16 \mathrm{mg} \cdot \mathrm{mL}^{-1}\right)$ were administered by inhalation for $90 \mathrm{~s}$, using a jet nebulizer (LC PLUS; Pari-Werk GmbH, Starnberg, Germany) driven by compressed air $\left(5 \mathrm{~L} \cdot \mathrm{min}^{-1}\right)$ and connected to the input port of the ventilator. Impedance spectra were ensembleaveraged at baseline, whereas individual ZL curves were fitted at 1-min intervals after MCh administration. Peak responses in $G$ at each dose were used for further analysis. Responses were measured as the percentage increase above the values obtained using saline. Evans blue (50 $\mathrm{mg} \cdot \mathrm{kg}^{-1}$ ) was administered by i.v. injection, over a 2-min period immediately after construction of $\mathrm{MCh}$ dose/ response curves. At the end of the experiment, $1.0 \mathrm{~mL}$ of blood was collected via cardiac puncture for the estimation of OVA-specific serum antibody titres.

\section{Bronchoalveolar lavage}

Animals were sacrificed and the chest opened $30 \mathrm{~min}$ after administration of Evans blue. BAL was performed via the tracheal cannula using three $8 \mathrm{~mL}$ aliquots of PBS containing lignocaine hydrochloride $(0.35 \%)$ and bovine serum albumin $(0.2 \%)$. Routinely $>90 \%$ of the lavage fluid was recovered from the lungs. The recovered fluid was centrifuged for $10 \mathrm{~min}$ at $250 \times g$ at $4^{\circ} \mathrm{C}$ and the cell pellet resuspended in $1.0 \mathrm{~mL}$ sterile PBS. The total cell count was determined by adding $20 \mu \mathrm{L}$ of the cell suspension to $20 \mu \mathrm{L}$ trypan blue and counting the cells using a light microscope and a Neubauer haemocytometer (BDH Laboratory Supplies, Poole, Dorset, UK). The differential cell count was carried out on cytospin preparations using Leishman's staining solution and counting 200 cells at random under 100 -fold magnification. The cells were identified by means of standard morphology.

The amount of Evans blue in the lavage fluid supernatant was quantified by measuring the absorbance at 630 $\mathrm{nm}$ using a spectrophotometer (Microplate AutoReader, model EL311; Bio-Tek Instruments Inc., Winooski, VT, USA). The concentration of dye was extrapolated from a standard curve $\left(1-10 \mu \mathrm{g} \cdot \mathrm{mL}^{-1}\right)$.

\section{Serum antibody measurements}

OVA-specific IgE titres were measured by enzymelinked immunosorbent assay (ELISA) according to the method of VAN Halteren et al. [16]. Briefly, microtitre plates (Falcon flexible assay plate 3912; Becton Dickinson, Bedford, MA, USA) were coated with mouse antirat IgE in PBS $\left(1 \mu \mathrm{g} \cdot \mathrm{mL}^{-1}\right)$ overnight at $4^{\circ} \mathrm{C}$. Doubling dilutions of standards and samples were added and incubated at room temperature (RT) for $3 \mathrm{~h}$. Digoxigenin-conjugated OVA was added $(1: 1,000)$ and incubated for $1 \mathrm{~h}$ at $\mathrm{RT}$, followed by sheep antidigoxigenin peroxidase conjugate $(1: 1,000)$ for $1 \mathrm{~h}$ at RT. The peroxidase substrate $3,3^{\prime}, 5,5^{\prime}$ tetramethylbenzidine (TMB) was used for colour development and the plates were read spectrophotometrically at $450 \mathrm{~nm}$ with an ELISA plate reader (Automated Microplate Reader, model EL311; Bio-Tek Instruments Inc.). Titres are expressed as reciprocal $\log _{2}$ litres.

\section{Drugs and materials}

L-arginine, L-NMMA, L-NAME, aminoguanidine, $S$ methyl-L-thiocitrulline, acetyl- $\beta$-methylcholine chloride (MCh), OVA (grade V), ricin, Evans blue, trypan blue and Leishman's stain were obtained from Sigma Chemical Company (St Louis, MO, USA). Mouse (monoclonal) antirat IgE was supplied by Biosource (Camarillo, CA, USA), digoxigenin-3-O-methylcarbonyl- $\varepsilon$-aminocaproic acid- $N$-hydroxysuccinimide ester, sheep antidigoxigen-inperoxidase Fab fragments from Roche Diagnostia (Basel, Switzerland) and TMB Peroxidase Substrate and Solution B from Kirkegaard \& Perry Laboratories (Gaithersburg, MD, USA). Bovine serum albumin was from CSL (Parkville, Victoria, Australia) and RPMI 1640 from Gibco BRL (Glen Waverley, Victoria, Australia). Ketamine (Keta-

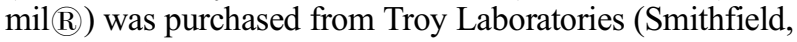

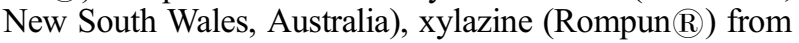
Bayder (Pymble, New South Wales, Australia), pancuro-

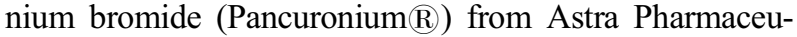
ticals (North Ryde, New South Wales, Australia) and pentobarbitone sodium (Lethabarbß) from Virbac (Peakhurst, New South Wales, Australia). The NOS inhibitors were freshly dissolved in sterile saline on the morning of each experiment. 


\section{Statistical analysis}

Comparisons for the total and differential cell counts, as well as Evans blue concentration in the BAL fluid and serum antibody levels between different treatment groups, were made using one-way analysis of variance (ANOVA) with Student-Newman-Keuls correction for multiple comparisons. The effect of pretreatment on MCh response was assessed by calculating the provocative concentration of MCh producing a 150 (PC150) or 250\% (PC250) increase in $G$ above baseline in naive or allergic animals respectively, by linear interpolation on a semilogarithmic $\mathrm{MCh}$ dose/response curve. Aerosolized MCh produces predominantly a tissue response [14]; thus only tissue mechanics were used in the statistical analysis. Comparisons between groups were made on log-transformed data using ANOVA. All results are expressed as mean \pm SEM. A p-value of $<0.05$ was regarded as statistically significant.

\section{Results}

In naive animals cumulative concentrations of inhaled MCh (2-16 mg. $\left.\mathrm{mL}^{-1}\right)$ induced a dose-dependent increase in $G$ with a PC150 of $7.84 \pm 0.62 \mathrm{mg} \cdot \mathrm{mL}^{-1}$ (table 1 ), and was associated with a corresponding dose-dependent increase in $H$. The changes in Raw and Iaw were less marked.

\section{The effect of nitric oxide synthase inhibition in naive animals}

Baseline lung mechanics. In naive, nonsensitized animals, pretreatment with L-NAME, L-arginine or its inactive enantiomer D-arginine (100 mg. $\mathrm{kg}^{-1}$ s.c.) produced no effect on baseline airway or tissue lung mechanics. There was no significant difference in body weight between the groups.

Table 1. - The effect of nitric oxide synthase inhibitors on responses to inhaled methacholine (MCh) in naive and sensitized rats

\begin{tabular}{lcccc}
\hline Pretreatment & $\begin{array}{c}\text { Challenge } \\
\text { exp } \\
\mathrm{n}\end{array}$ & $\begin{array}{c}\mathrm{PC} 150 \\
\mathrm{mg} \cdot \mathrm{mL}^{-1}\end{array}$ & $\begin{array}{c}\mathrm{PC} 250 \\
\mathrm{mg} \cdot \mathrm{mL}^{-1}\end{array}$ \\
\hline Naive & & & & \\
Saline & Saline & 8 & $7.84 \pm 0.62$ & - \\
D-Arginine & Saline & 5 & $7.09 \pm 1.01$ & - \\
L-Arginine & Saline & 6 & $8.95 \pm 1.52$ & - \\
L-NAME & Saline & 6 & $3.59 \pm 1.06^{+}$ & - \\
Sensitized & & & & $13.55 \pm 1.26$ \\
Saline & Saline & 8 & - & $8.77 \pm 0.99^{++}$ \\
Saline & OVA & 9 & - & $7.75 \pm 0.94$ \\
D-Arginine & OVA & 5 & - & $8.73 \pm 2.30$ \\
L-Arginine & OVA & 4 & - & $6.95 \pm 1.24^{*}$ \\
L-NMMA & OVA & 8 & - & $4.98 \pm 0.57^{*}$ \\
L-NAME & OVA & 5 & - & $10.39 \pm 1.37$ \\
Aminoguanidine & OVA & 9 & - & \\
S-methyl-L- & & & & $3.10 \pm 0.75^{* * *}$ \\
thiocitrulline & OVA & 6 & - & \\
\hline
\end{tabular}

Data are presented as mean \pm SEM. $\mathrm{PC} 150$ and $\mathrm{PC} 250$ : provocative concentrations of MCh producing 150 and $250 \%$ increases in frequency-dependent tissue resistance; exp: experiments; LNAME: $N^{\omega}$-nitro-L-arginine methyl ester; L-NMMA: $N^{\mathrm{G}}$-monomethyl-L-arginine; OVA: ovalbumin. ${ }^{+}: \mathrm{p}<0.05$ versus naive animals pretreated with saline; ${ }^{++}: \mathrm{p}<0.01$ versus sensitized animals pretreated with saline; *: $\mathrm{p}<0.05 ; * *$ : $\mathrm{p}<0.01 ; * * *$ : $\mathrm{p}<0.001$ versus sensitized animals pretreated with saline and challenged with OVA.
Response to methacholine. Pretreatment of naive animals with L-arginine or D-arginine did not alter the tissue responses to inhaled MCh (table 1). L-NAME (100 mg. $\mathrm{kg}^{-1}$ s.c.) potentiated responses to $\mathrm{MCh}$, inducing a greater than two-fold shift to the left of the MCh dose/response curve and reducing the PC150 to $3.59 \pm 1.06 \mathrm{mg} \cdot \mathrm{mL}^{-1}$ $(\mathrm{p}<0.05)$ (table 1). With L-NAME pretreatment, the response at the maximal concentration of spasmogen (16 $\mathrm{mg} \cdot \mathrm{mL}^{-1}$ ) was significantly increased above baseline $(p<0.001)$ (table 2). This effect was reversible with concurrent administration of L-arginine (results not shown).

Inflammatory cell migration. L-arginine induced an increase in the total number of inflammatory cells recovered from the lungs of naive animals $(n=6, p<0.001)$, and this was associated with increased numbers of macrophages $(\mathrm{p}<0.001)$, lymphocytes $(\mathrm{p}<0.001)$ and neutrophils $(\mathrm{p}<$ 0.001 ) in the lavage fluid (table 3 ). Pretreatment of naive animals with L-NAME or D-arginine had no effect on the cellular content of the BAL fluid.

Microvascular permeability. L-Arginine pretreatment significantly increased the concentration of Evans blue in the lavage fluid of naive animals from $1.87 \pm 0.05 \mathrm{mg} \cdot \mathrm{mL}^{-1}$ to $2.81 \pm 0.19 \mathrm{mg} \cdot \mathrm{mL}^{-1}(\mathrm{n}=6, \mathrm{p}<0.001)$ (fig. 2). Pretreatment with D-arginine or L-NAME produced no effect on vascular permeability.

\section{The effect of NOS inhibitors in allergic animals}

Sensitization of animals with OVA resulted in an increase in OVA-specific serum IgE levels from a mean titre of $2.75 \pm 0.22 \log _{2}{ }^{-1}$ to $7.32 \pm 0.29 \log _{2}{ }^{-1}(\mathrm{p}<0.001$, $\mathrm{n}=9)$. Pre-treatment with NOS inhibitors $\left(100 \mathrm{mg} \cdot \mathrm{kg}^{-1}\right.$ s.c. $)$ produced no effect on serum IgE levels.

Table 2. - The effect of nitric oxide synthase inhibitors on maximal response to inhaled methacholine (MCh) (16 $\mathrm{mg} \cdot \mathrm{mL}^{-1}$ ) in naive and sensitized rats

\begin{tabular}{lcclll}
\hline Pretreatment & Challenge & $\mathrm{n}$ & $R$ aw $\% \mathrm{BL}$ & $G \% \mathrm{BL}$ & $H \% \mathrm{BL}$ \\
\hline $\begin{array}{l}\text { Naive } \\
\text { Saline }\end{array}$ & Saline & 8 & $19 \pm 9$ & $227 \pm 11$ & $125 \pm 13$ \\
D-Arginine & Saline & 5 & $27 \pm 15$ & $279 \pm 27$ & $97 \pm 12$ \\
L-Arginine & Saline & 6 & $27 \pm 7$ & $240 \pm 23$ & $119 \pm 15$ \\
L-NAME & Saline & 6 & $39 \pm 16$ & $336 \pm 15^{+++}$ & $140 \pm 6+$ \\
Sensitized & & & & & \\
Saline & Saline & 8 & $22 \pm 12$ & $232 \pm 23$ & $119 \pm 6$ \\
Saline & OVA & 9 & $47 \pm 16^{+}$ & $346 \pm 19^{+++}$ & $134 \pm 8^{++}$ \\
$\begin{array}{l}\text { D-Arginine } \\
\text { L-Arginine }\end{array}$ & OVA & 5 & $59 \pm 13$ & $347 \pm 26$ & $129 \pm 30$ \\
L-NMMA & OVA & 4 & $54 \pm 16$ & $300 \pm 33$ & $118 \pm 6$ \\
L-NAME & OVA & 5 & $72 \pm 11$ & $425 \pm 23^{*}$ & $170 \pm 20^{*}$ \\
$\begin{array}{l}\text { Aminoguani- } \\
\text { dine }\end{array}$ & OVA & 9 & $34 \pm 13$ & $314 \pm \pm 35^{* *}$ & $168 \pm 11^{*}$ \\
$\begin{array}{l}\text { S-methyl-L- } \\
\text { thiocitrulline }\end{array}$ & OVA & 6 & $38 \pm 22$ & $538 \pm 41^{* * *}$ & $173 \pm 9^{* *}$ \\
\hline
\end{tabular}

Data are presented as mean percentage increase ablove baseline $(\% \mathrm{BL}) \pm$ SEM. Raw: airway resistance; $G$ : frequency-dependent tissue resistance; $H$ : tissue elastance; exps: experments; LNAME: $N^{\omega}$-nitro-L-arginine methyl ester; L-NMMA: $N^{\mathrm{G}}$-monomethyl-L-arginine; OVA: ovalbumin. ${ }^{+}: \mathrm{p}<0.05 ;{ }^{++}: \mathrm{p}<0.01 ;{ }^{+++}$: $\mathrm{p}<0.001$ versus saline pretreatment; $*$ : $\mathrm{p}<0.05 ;{ }^{* *}: \mathrm{p}<0.01 ; * * *$ : $\mathrm{p}<0.001$ versus sensitized animals pretreated with saline and exposed to OVA. 
Table 3. - The effect of nitric oxide synthase inhibitors on total and differential cell counts in naive and sensitized rats

\begin{tabular}{|c|c|c|c|c|c|c|}
\hline Pretreatment & Challenge & Total & Macrophage & Lymphocyte & Eosinophil & Neutrophil \\
\hline \multicolumn{7}{|l|}{ Naive } \\
\hline Saline & Saline & $0.62 \pm 0.02$ & $0.40 \pm 0.02$ & $0.18 \pm 0.01$ & 0 & $0.03 \pm 0.01$ \\
\hline D-Arginine & Saline & $0.60 \pm 0.03$ & $0.43 \pm 0.02$ & $0.15 \pm 0.03$ & 0 & $0.02 \pm 0.01$ \\
\hline L-Arginine & Saline & $1.85 \pm 0.22^{+++}$ & $1.24 \pm 0.15^{+++}$ & $0.34 \pm 0.04^{+++}$ & 0 & $0.17 \pm 0.06^{+++}$ \\
\hline L-NAME & Saline & $0.75 \pm 0.07$ & $0.52 \pm 0.04$ & $0.17 \pm 0.03$ & 0 & $0.06 \pm 0.02$ \\
\hline \multicolumn{7}{|l|}{ Sensitized } \\
\hline Saline & Saline & $0.64 \pm 0.04$ & $0.44 \pm 0.02$ & $0.18 \pm 0.04$ & 0 & $0.02 \pm 0.01$ \\
\hline Saline & OVA & $4.16 \pm 0.19^{+++}$ & $1.59 \pm 0.10^{+++}$ & $2.15 \pm 0.15^{+++}$ & $0.16 \pm 0.03^{+++}$ & $0.26 \pm 0.03^{+++}$ \\
\hline D-Arginine & OVA & $3.99 \pm 0.21$ & $1.52 \pm 0.09$ & $2.06 \pm 0.10$ & $0.14 \pm 0.01$ & $0.26 \pm 0.03$ \\
\hline L-Arginine & OVA & $5.26 \pm 0.41 *$ & $2.27 \pm 0.62 *$ & $2.75 \pm 0.86$ & $0.09 \pm 0.05$ & $0.15 \pm 0.06$ \\
\hline L-NMMA & OVA & $1.14 \pm 0.23 * * *$ & $0.52 \pm 0.11 * * *$ & $0.32 \pm 0.06 * * *$ & $0.05 \pm 0.01 * *$ & $0.09 \pm 0.02 * *$ \\
\hline L-NAME & OVA & $4.49 \pm 0.42$ & $2.19 \pm 0.44$ & $1.94 \pm 0.22$ & $0.10 \pm 0.01$ & $0.26 \pm 0.05$ \\
\hline Aminoguanidine & OVA & $0.75 \pm 0.08 * * *$ & $0.32 \pm 0.03 * * *$ & $0.33 \pm 0.06^{* * *}$ & $0.04 \pm 0.004 * * *$ & $0.07 \pm 0.02 * * *$ \\
\hline$S$-methyl-L-thiocitrulline & OVA & $4.27 \pm 0.51$ & $2.00 \pm 0.25$ & $2.03 \pm 0.32$ & $0.12 \pm 0.02$ & $0.13 \pm 0.05$ \\
\hline
\end{tabular}

Data are presented as mean \pm SEM. L-NAME: $N^{\omega}$-nitro-L-arginine methyl ester; L-NMMA: $N^{\mathrm{G}}$-mono-methyl-L-arginine; OVA: ovalbumin. ${ }^{+++}: \mathrm{p}<0.001$ versus saline pretreatment; $*: \mathrm{p}<0.05 ; * *: \mathrm{p}<0.01 ; * * *: \mathrm{p}<0.001$ versus sensitized animals challenged with $\mathrm{OVA}$.

Baseline lung mechanics. In sensitized animals, the baseline Raw was increased from $57 \pm 6 \mathrm{cmH} \mathrm{H}_{2} \mathrm{O} \cdot \mathrm{s} \cdot \mathrm{L}^{-1}$ in salinechallenged animals to $75 \pm 2 \mathrm{~cm} \mathrm{cmH} \mathrm{CH}_{2} \mathrm{O} \cdot \mathrm{s} \cdot \mathrm{L}^{-1} 24 \mathrm{~h}$ after OVA challenge $(\mathrm{p}<0.01, \mathrm{n}=9)$. Pretreatment with L-arginine, D-arginine or any of the NOS inhibitors produced no further change in Raw in sensitized and allergen-challenged animals. The baseline tissue parameters $G$ and $H$ were not affected by OVA challenge in sensitized animals or by any drug pretreatment (results not shown).

Hyperresponsiveness to methacholine. Exposure of sensitized animals to a single aerosol challenge of OVA produced a significant increase in frequency-dependent tissue responsiveness $(G)$ to $\mathrm{MCh} 24 \mathrm{~h}$ later (table 1). The MCh dose/response curve was shifted to the left compared with sensitized animals exposed to an aerosol of saline, reducing the $\mathrm{PC} 250$ from $13.55 \pm 1.26 \mathrm{mg} \cdot \mathrm{mL}^{-1}$ to $8.77 \pm 0.99$ $\mathrm{mg} \cdot \mathrm{mL}^{-1}($ table 1$)$. The peak tissue $G$ response at the highest dose of MCh $\left(16 \mathrm{mg} \cdot \mathrm{mL}^{-1}\right)$ was increased from $232 \pm 23$ to $346 \pm 19 \%$ above baseline after OVA challenge (table 2).

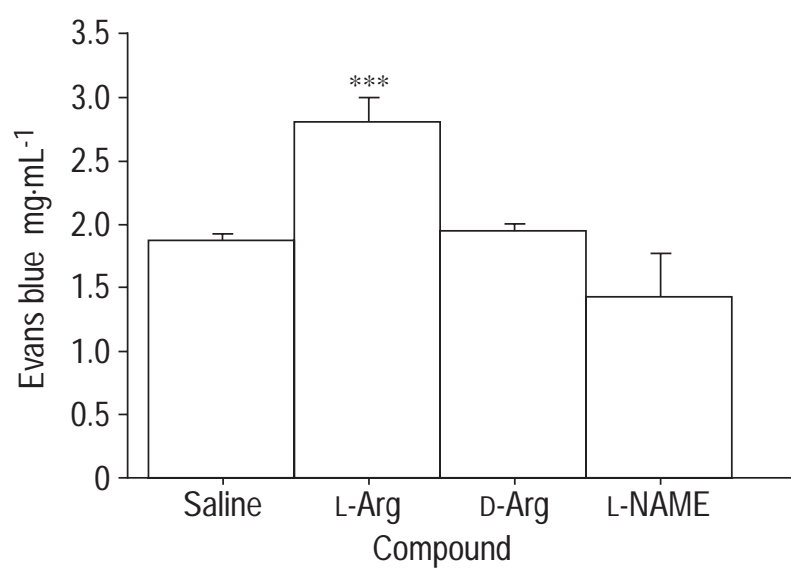

Fig. 2. - Effect of nitric oxide synthase inhibitors on microvascular permeability in naive rats. Concentration of Evans blue in the bronchoalveolar lavage fluid of naive animals pretreated with saline $(n=8)$, Larginine (L-Arg; $\mathrm{n}=6$ ), D-arginine $(\mathrm{D}-\mathrm{Arg} ; \mathrm{n}=5)$ or $N^{(\omega)}$-nitro-L-arginine methyl ester (L-NAME; $\mathrm{n}=6$ ). Data are expressed as mean \pm SEM. ***: $\mathrm{p}<0.001$ versus saline pretreatment.
L-NMMA, L-NAME and $S$-methyl-L-thiocitrulline further potentiated the OVA-induced hyperresponsiveness in sensitized animals, causing a significant leftward shift of the $\mathrm{MCh}$ dose/response curve and reducing the $\mathrm{PC} 250$ to $6.95 \pm 1.24 \mathrm{mg} \cdot \mathrm{mL}^{-1}, 4.98 \pm 0.57 \mathrm{mg} \cdot \mathrm{mL}^{-1}$ and $3.10 \pm 0.75$ $\mathrm{mg} \cdot \mathrm{mL}^{-1}$, respectively (table 1 ). Furthermore, the peak $G$ response at $16 \mathrm{mg} \cdot \mathrm{mL}^{-1}$ was further potentiated from $346 \pm 19 \%$ above baseline to $425 \pm 23 \%$ with L-NMMA, $476 \pm 18 \%$ with L-NAME and $538 \pm 11 \%$ with $S$-methyl-Lthiocitrulline (table 2). Parenchymal responses to inhaled MCh were not influenced by pretreatment with L-arginine, D-arginine or aminoguanidine (tables 1 and 2).

Inflammatory cell migration. Exposure of sensitized animals to OVA resulted in a greater than six-fold increase in the number of inflammatory cells present in the BAL fluid $(n=9, p<0.001)$ (table 3$)$ as a result of increased numbers of eosinophils $(p<0.001)$, lymphocytes $(p<0.001)$, macrophages $(\mathrm{p}<0.001)$ and neutrophils $(\mathrm{p}<0.001)$ (table 3$)$.

Pretreatment with L-arginine further increased the OVAinduced inflammatory cell influx $(n=4, p<0.05)$ (table 3$)$, predominantly as a result of macrophage influx $(\mathrm{p}<0.05)$ into the BAL fluid (table 3). D-arginine produced no effect (table 3).

Aminoguanidine was effective in attenuating the allergen-induced cellular influx, reducing the total cell count from $4.16 \pm 0.19 \times 10^{6}$ cells $\cdot \mathrm{mL}^{-1}$ to $0.75 \pm 0.08 \times 10^{6}$ cells. $\mathrm{mL}^{-1}(\mathrm{n}=9, \mathrm{p}<0.001)($ table 3$)$ and significantly inhibiting the influx of eosinophils $(\mathrm{p}<0.001)$, lymphocytes $(\mathrm{p}<$ $0.001)$, macrophages $(p<0.001)$ and neutrophils $(p<0.001)$ into the lavage fluid (table 3 ). This effect was reversible with concurrent administration of L-arginine, increasing the total cell count to $3.53 \pm 0.58 \times 10^{6}$ cells $\cdot \mathrm{mL}^{-1}$ in aminoguanidine-pretreated animals $(\mathrm{n}=6, \mathrm{p}<0.001)$. L-NMMA pretreatment produced similar effects to those of aminoguanidine, significantly reducing the cellular influx associated with allergen exposure $(n=8, p<0.001)($ table 3$)$ and suppressing the number of eosinophils $(\mathrm{p}<0.01)$, lymphocytes $(\mathrm{p}<0.001)$ macrophages $(\mathrm{p}<0.001)$, and neutrophils $(\mathrm{p}<0.01)$ (table 3$)$.

Pretreatment with L-NAME or $S$-methyl-L-thiocitrulline produced no effect on OVA-induced influx of inflammatory cells into the BAL fluid (table 3 ) or the differential cell count in these animals (table 3 ). 
Microvascular permeability. Exposure of sensitized animals to OVA produced a greater than two-fold increase in the concentration of Evans blue in the BAL fluid, which increased from $1.95 \pm 0.02 \mathrm{mg} \cdot \mathrm{mL}^{-1}$ in sensitized animals exposed to saline to $4.36 \pm 0.21 \mathrm{mg} \cdot \mathrm{mL}^{-1}$ after OVA exposure $(n=9, p<0.001)$ (fig. 3). L-arginine pretreatment produced a further increase in the concentration of Evans blue dye in the lavage fluid to $5.83 \pm 0.27 \mathrm{mg} \cdot \mathrm{mL}^{-1}(\mathrm{n}=4$, $\mathrm{p}<0.05$ ) which was not evident in $\mathrm{D}$-arginine-pretreated animals.

Aminoguanidine significantly inhibited the allergeninduced increase in microvascular leakage with the concentration of Evans blue in the BAL fluid $(2.12 \pm 0.14$ $\mathrm{mg} \cdot \mathrm{mL}^{-1}$ ) being significantly lower than that in the sensitized-OVA-challenged group $(\mathrm{p}<0.001)$ (fig. 3$)$. This effect was counteracted by the concurrent administration of L-arginine $\left(5.03 \pm 0.64 \mathrm{mg} \cdot \mathrm{mL}^{-1} ; \mathrm{n}=6 \mathrm{p}<0.001\right)$. L-NMMA produced a similar effect to aminoguanidine $(2.33 \pm$ $\left.0.25 \mathrm{mg} \cdot \mathrm{mL}^{-1} ; \mathrm{n}=8, \mathrm{p}<0.001\right)$, whereas L-NAME $(4.64 \pm$ $\left.0.40 \mathrm{mg} \cdot \mathrm{mL}^{-1}\right)$ and $S$-methyl-L-thiocitrulline $(4.62 \pm 0.41$ $\mathrm{mg} \cdot \mathrm{mL}^{-1}$ ) were without effect.

\section{Discussion}

The results of the present study are consistent with the suggestion that NO produced by iNOS contributes to the inflammatory cell influx and increased epithelial permeability seen $24 \mathrm{~h}$ after allergen challenge in sensitized rats, whereas NO produced by the constitutively expressed nNOS acts to inhibit the hyperresponsiveness to methacholine. These data demonstrate the importance of NO in the pulmonary response to allergen challenge in sensitized animals and highlight the local nature of the influence of NO.

Before considering the implications of the present data, several technical details of the approach used need to be examined. The ability of the constant-phase model to give an accurate description of the tissue mechanics and enable

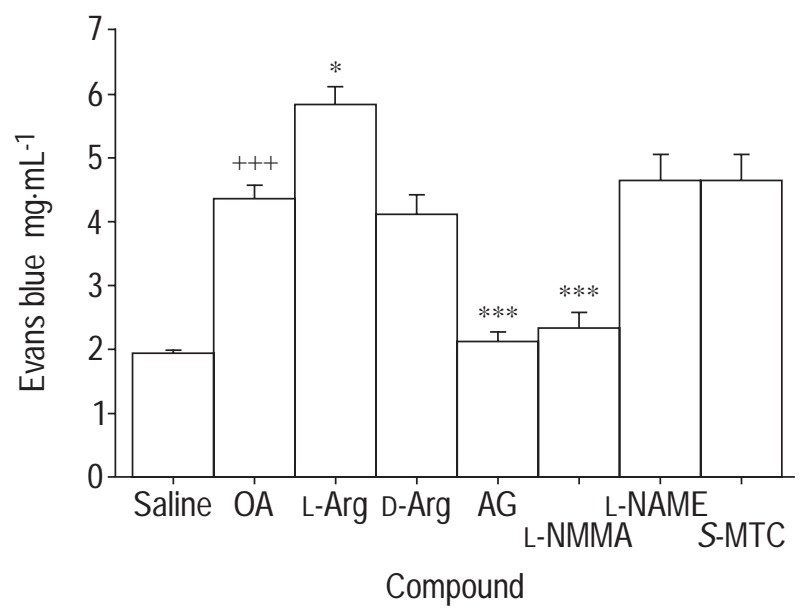

Fig. 3. - Effect of nitric oxide synthase inhibitors on microvascular permeability in sensitized rats. Concentration of Evans blue in the bronchoalveolar lavage fluid of sensitized and ovalbumin (OVA)-challenged animals $(n=9)$ pretreated with $L$-arginine $(L-A r g ; n=4)$, D-arginine (D-Arg; $\mathrm{n}=5$ ), aminoguanidine ( $\mathrm{AG} ; \mathrm{n}=9), N^{\mathrm{G}}$-mono-methyl-L-arginine (L-NMMA; $\mathrm{n}=8$ ), $N^{\omega}$-nitro-L-arginine methyl ester (L-NAME; $\mathrm{n}=5$ ) or $S$ methyl-L-thiocitrulline (S-MTC; $n=6$ ). Data are expressed as mean \pm SEM. ${ }^{++}: \mathrm{p}<0.001$ versus sensitized animals challenged with saline; $*: \mathrm{p}<$ $0.05 ; * * *: \mathrm{p}<0.001$ versus sensitized animals challenged with OVA. the airway and parenchymal components of the total impedance spectra to be separated has been demonstrated in several species, including the rat, under control and constricted conditions $[14,17,18]$. The predominance of parenchymal over airway responses to inhaled $\mathrm{MCh}$ in naive animals has previously been reported, the aerosol delivery of MCh inducing a greater increase in $G$ than in Raw [14]. In the present study using the forced oscillation technique, the maximal concentration of inhaled $\mathrm{MCh}$ used produced small increases in Raw $(47 \pm 16 \%)$ and a $366 \pm 19 \%$ increase above baseline in $G$ after OVA exposure in sensitized animals. Thus, this technique is ideally suited for examining parenchymal or tissue responses to inhaled MCh. Peripheral airways, including lung tissue are an important site for the development of bronchial hyperresponsiveness and an important site of airflow obstruction in asthmatics [19-21]. The doses used in this study were chosen to avoid significant systemic effects of MCh, which can complicate the interpretation of changes in lung mechanics.

Interpretation of the present data is critically dependent on the relative selectivity of the NOS enzyme inhibitors used. In the rat, $S$-methyl-L-thiocitrulline exhibits $>100$-fold selectivity for rat nNOS $(50 \%$ inhibitory concentrations $(\mathrm{IC} 50)=0.3 \mu \mathrm{M})$ compared to the inducible enzyme iNOS (IC50=34 $\mu \mathrm{M}$ ) and 17-fold selectivity for rat nNOS in neuronal tissue compared to rat eNOS in vascular endothelium, suggesting that $S$-methyl-L-thiocitrulline may be selective for nNOS in vivo [22]. L-NAME is reported to be very selective for cNOS, especially eNOS, with an IC50 of $0.5 \mu \mathrm{M}$ compared to $>1,000 \mu \mathrm{M}$ for iNOS [23, 24]. No separate data are available for nNOS. L-NMMA is nonselective, with IC50 values of $0.7,3.9$ and $0.65 \mathrm{mM}$ for eNOS, iNOS and nNOS, respectively [25]. Aminoguanidine was the least specific of the agents used with an IC 50 of $250 \mu \mathrm{M}$ for iNOS compared to $526 \mu \mathrm{M}$ for eNOS $[26,27]$. No data are available regarding its selectivity for nNOS. Although the relative selectivity of these agents is not absolute, there is a marked degree of internal consistency in the present data.

In order to examine the effects of NOS inhibitors in the present model of allergen-induced pulmonary inflammation and airway hyperresponsiveness, NOS inhibitors were administered on 3 consecutive days at $100 \mathrm{mg} \cdot \mathrm{kg}^{-1} \cdot \mathrm{day}^{-1}$, the last dose being administered $1 \mathrm{~h}$ prior to anaesthesia and $23 \mathrm{~h}$ after allergen challenge. These doses were the same as those previously reported by TsUKAGOSHI et al. [10] in the rat. Similarly, the differential effects of aminoguanidine and L-NAME at these doses were shown by ANDERSSON et al. [28] in Sephadex-induced inflammation in the rat lung. The present results show both aminoguanidine and L-NMMA to inhibit allergen-induced inflammatory cell influx and increase epithelial permeability in sensitized animals $24 \mathrm{~h}$ after allergen challenge, whereas the cNOS inhibitors produce no effect. The NOS substrate, L-arginine increased both of these phenomena, whereas D-arginine produce no effect confirming the role of NO in producing them. The cNOS- and nNOSselective inhibitors, as well as the nonselective L-NMMA, but not aminoguanidine potentiated $\mathrm{MCh}$ responsiveness and L-arginine reduced it, strongly suggesting a role NO, and in particular of that produced by nNOS, in opposing this manifestation of the late-phase allergen response. The present model measured these three components of the 
late-phase response to allergen challenge at the same time in the same animal. Had nonselective doses of the NOS isoenzyme inhibitors been used, the differential responses reported in the present manuscript would not have been seen.

In the present study, inhibition of nNOS by L-NAME in naive nonallergic animals potentiated responsiveness to MCh but L-arginine produced no effect. This pattern of response would suggest that nNOS is constitutively expressed but not substrate-limited. The NO produced may play a role in limiting parenchymal responses to the cholinergic nervous system (as mimicked by the MCh challenge). In addition, allergic animals show hyperresponsiveness to MCh $24 \mathrm{~h}$ after OVA challenge. Under these circumstances, inhibition of nNOS further increases the parenchymal response to the spasmogen and pretreatment with Larginine reduced this response. These results are in agreement with published literature suggesting that dysfunction of NO-mediated inhibitory nonadrenergic noncholinergic neurotransmission exaggerates bronchoconstriction in a rat model of inflammatory condition [29]. Furthermore, it suggests that following allergen challenge nNOS becomes substrate-limited possibly because the enzyme activity is upregulated or because L-arginine is consumed elsewhere (by increased iNOS activity for example).

Unlike the inhibition of cNOS and nNOS isoenzymes, this study demonstrates that preferential iNOS inhibition with aminoguanidine protects against allergen-induced cellular influx and microvascular leakage without altering responses to $\mathrm{MCh}$. Pretreatment with aminoguanidine completely inhibited the migration of eosinophils, lymphocytes, macrophages and neutrophils into the lungs of sensitized animals after allergen challenge. These findings are in agreement with published literature suggesting aminoguanidine has beneficial effects in various experimental models of inflammation $[30,31]$ and shock $[32$, 33]. Contrary to the results of this study in the rat, a recent study by FEDER et al. [34] demonstrated in the mouse that the selective iNOS inhibitor, L-N $\mathrm{N}^{6}$-(1-Imminethyl) lysine (L-NIL), was ineffective in reducing the allergen-induced eosinophilia. This potential species difference in the regulation of NO produced by iNOS suggests that in the rat an additional NO-independent mechanism, which is absent in the mouse may be involved in regulation of cellular influx following allergen challenge.

eNOS is found predominantly in the vascular endothelium and is thought to generate NO which acts to lower blood pressure and inhibit the adhesion and activation of platelets and polymorphonuclear granulocytes [35]. The lack of effects of eNOS inhibition with L-NAME on cellular influx and vascular permeability in the present model was a surprising outcome and, since L- NAME has been shown to be 2,000 times more selective for eNOS than iNOS [24], these results would therefore suggest this isoenzyme to be selectively involved in the regulation of vascular tone and not in cell recruitment or plasma exudation. Furthermore, the present results are in agreement with recently published literature in rats suggesting L-NAME has no effect on the cellular migration at 6 or 24 $\mathrm{h}$ after allergen challenge [11]. However, in that study LNAME was effective in abolishing the allergen-induced eosinophilia $48 \mathrm{~h}$ after allergen exposure. Similarly, IIJIMA et al. [36] also demonstrated a significant inhibitory effect of L-NAME on late-phase allergen-induced eosinophil influx and airway microvascular permeability in guineapigs, suggesting a role for cNOS in inflammatory cell trafficking $48 \mathrm{~h}$ after allergen challenge.

In summary, the present findings are consistent with the notion that nitric oxide production by inducible nitric oxide synthase plays a role in the migration of inflammatory cells and increase in vascular permeability $24 \mathrm{~h}$ following allergen challenge, whereas nitric oxide produced by neuronal nitric oxide synthase limits hyperresponsiveness to methacholine. These findings highlight the complexity of the nitric oxide synthase system and suggest that any therapeutic strategy for human asthma targeting nitric oxide would need to be thoroughly investigated.

Acknowledgements. The authors would especially like to thank the technical staff at the Research Centre as well as P. Burton and $\mathrm{K}$. Tiller for their statistical expertise.

\section{References}

1. Moncada S, Higgs EA. Molecular mechanisms and therapeutic strategies related to nitric oxide. FASEB $J$ 1995; 9: 1319-1330.

2. Kuo HP, Liu S, Barnes PJ. The effect of endogenous nitric oxide on neurogenic plasma exudation in guinea pig airways. Eur J Pharmacol 1992; 221: 385-388.

3. Alving KE, Weitzberg JM, Lundberg JM. Increased amount of nitric oxide in exhaled air of asthmatics. Eur Respir J 1993; 6: 1368-1370.

4. Barnes PJ. NO or no NO in asthma? Thorax 1996; 51: 218-220.

5. Kharitonov SA, Yates D, Robbins RA, Logan-Sinclair R, Shinebourne EA, Barnes PJ. Increased nitric oxide in exhaled air of asthmatic patients. Lancet 1994; 343: 133135.

6. Massaro AF, Gaston B, Kita D, Fanta C, Stamler JS, Drazen JM. Expired nitric oxide levels during treatment of acute asthma. Am J Respir Crit Care Med 1995; 152: 800-803.

7. Hamid Q, Springall DR, Riveros-Moreno V, et al. Induction of nitric oxide synthase in asthma. Lancet 1993; 342: $1510-1513$.

8. Kips JC, Lefebvre RA, Peleman RA, Joos GF, Pauwels RA. The effect of a nitric oxide synthase inhibitor on the modulation of airway responsiveness in rats. Am J Respir Crit Care Med 1995; 151: 1165-1169.

9. Bernanereggi M, Mitchell JA, Barnes PJ, Belvisi MG. Dual action of nitric oxide on airway plasma leakage. $\mathrm{Am}$ J Respir Crit Care Med 1997; 155: 869-874.

10. Tsukagoshi H, Robbins RA, Barnes PJ, Chung KF. Role of nitric oxide and superoxide anions in interleukin- $1 \beta$ induced airway hyperresponsiveness to bradykinin. $\mathrm{Am} J$ Respir Crit Care Med 1994; 150: 1019-1025.

11. Ferreira HHA, Bevilacqua E, Gagioti SM, et al. Nitric oxide modulates eosinophil infiltration in antigen-induced airway inflammation in rats. Eur J Pharmacol 1998; 358: 253-259.

12. Smith SR, Petillo J. IgE production in five inbred rat strains following immunization with alum-precipitated egg albumin. Int Arch Allergy Appl Immunol 1976; 52: 21-31.

13. Pauwels R, Bazin H, Platteau B, Van der Straeten M. The influence of antigen-dose on IgE production in different strains. Immunology 1979; 36: 151-157. 
14. Peták, F, Hantos Z, Adamicza Á, Asztalos T, Sly PD. Methacholine-induced bronchoconstriction in rats: effects of intravenous vs. aerosol delivery. J Appl Physiol 1997; 82: $1479-1487$.

15. Hantos Z, Adamicza A, Govaerts E, Doroczy B. Mechanical impedances of lungs and chest wall in the cat. $J \mathrm{Appl}$ Physiol 1992; 73: 427-433.

16. Van Halteren AGS, Van Der Cammen MJF, Biewenga J, Savelkoul HFJ, Kraal G. IgE and mast cell responses on intestinal allergen exposure: a murine model to study the onset of food allergy. J Allergy Clin Immunol 1997; 99: 94-99.

17. Hantos Z, Peták F, Adamicza Á, Daroczy B, Fredberg JJ. Histamine-induced constriction of the dog lung: differential responses of global airway, terminal airway, and tissue impedances. J Appl Physiol 1995; 79: 1440-1448.

18. Lutchen KR, Hantos Z, Peták F, Adamicza Á, Suki B. Airway inhomogeneities contribute to apparent lung tissue mechanics during constriction. J Appl Physiol 1996; 80: $1841-1849$.

19. Ohrui T, Sekizawa K, Yanai M, et al. Partitioning of pulmonary responses to inhaled methacholine in subjects with asymptomatic asthma. Am Rev Respir Dis 1992; 146: 1501-1505.

20. Yanai M, Ohrui T, Sekizawa K, Shimizu Y, Sasaki H, Takishima T. Effective site of bronchodilation by antiasthma drugs in subjects with asthma. J Allergy Clin Immunol 1991; 87: 1080-1087.

21. Yanai M, Sekizawa K, Ohrui T, Sasaki H, Takishima T. Site of airway obstruction in pulmonary disease: direct measurement of intrabronchial pressure. J Appl Physiol 1992; 72: 1016-1023.

22. Furfine ES, Harmon MF, Paith JE, et al. Potent and selective inhibition of human nitric oxide syntheses. $J$ Biol Chem 1994; 269: 26677-26683.

23. Gross SS, Stuchr DJ, Aisaka K, Jaffe EA, Levi R, Griffith OW. Macrophage and endothelial cell nitric oxide synthesis: cell-type selective inhibition by $N^{\mathrm{G}}$ - aminoarginine, $N^{\mathrm{G}}$-nitroarginine and $N^{\mathrm{G}}$-methylarginine. Biochem Biophys Res Commun 1990; 170: 96-103.

24. Dawson VL, Dawson TM, London ED, Bredt DS, Snyder SH. Nitric oxide mediates glutamate neurotoxicity in primary cortical cultures. Proc Natl Acad Sci USA 1991; 88: 6368-6371.

25. Reif DW, McCreedy SA. N-nitro-L-arginine and Nmonomethyl-L-arginine exhibit a different pattern of inactivation toward the three nitric oxide syntheses. Arch Biochem Biophys 1995; 320: 170-176.

26. Wolff DJ, Lubeskie A. Aminoguanidine is an isoformselective, mechanism-based inactivator of nitric oxide synthase. Arch Biochem Biophys 1995; 316: 290-301.

27. Griffiths MJD, Messent M, MacAllister RJ, Evans TW. Aminoguanidine selectively inhibits inducible nitric oxide synthase. Br J Pharmacol 1993; 110: 963-968.

28. Andersson SE, Kallstrom L, Malm M, Miller-Larsson A, Axelsson B. Inhibition of nitric oxide synthase reduces Sephadex-induced oedema formation in the rat lung: dependence on intact adrenal function. Inflamm Res 1995; 44: 418-422.

29. Belvisi MG, Ward JK, Mitchell JA, Barnes PJ. Nitric oxide as a neurotransmitter in human airways. Arch Int Pharmacodyn Ther 1995; 329: 97-110.

30. Mikawa K, Nishina K, Tamada M, Takao Y, Maekawa N, Obara H. Aminoguanidine attenuates endotoxin-induced acute lung injury in rabbits. Crit Care Med 1998; 26: 905-911.

31. Wu CC, Ruetten H, Thiemermann C. Comparison of the effects of aminoguanidine and $N$-omega-nitro-L-arginine methyl ester on the multiple organ dysfunction caused by endotoxaemia in the rat. Eur J Pharmacol 1996; 300: 99104.

32. Wright CE, Rees DD, Moncada S. Protective and pathological roles of nitric oxide in endotoxin shock. Cardiovasc Res 1992; 26: 48-57.

33. Vallance P, Moncada S. Role of endogenous nitric oxide in septic shock. New Horiz 1993; 1: 77-86.

34. Feder LS, Stelts D, Chapman RW, et al. Role of nitric oxide on eosinophilic lung inflammation in allergic mice. Am J Respir Cell Mol Biol 1997; 17: 436-442.

35. Moncada S, Palmer RMJ, Higgs EA. Nitric oxide: physiology, pathophysiology, and pharmacology. Pharmacol Rev 1991; 43: 109-142.

36. Iijima H, Uchida Y, Endo T, et al. Role of endogenous nitric oxide in allergen-induced airway responses in guinea-pigs. Br J Pharmacol 1998; 124: 1019-1028. 